\title{
FRUCTOSE DURING PREGNANCY PROVOKES FETAL OXIDATIVE STRESS: THE KEY ROLE OF THE PLACENTAL HEME OXYGENASE-1
}

\author{
Silvia Rodrigo, Lourdes Rodríguez, Paola Otero, María I. Panadero, Antonia García ${ }^{1}$, Coral \\ Barbas $^{1}$, Núria Roglans ${ }^{2}$, Sonia Ramos ${ }^{3}$, Luis Goya ${ }^{3}$, Juan C. Laguna ${ }^{2}$, Juan J. Álvarez-Millán ${ }^{4}$, \\ and Carlos Bocos.
}

Facultad de Farmacia, Universidad San Pablo-CEU, Montepríncipe, Boadilla del Monte, Madrid, Spain. ${ }^{(1)}$ Centre of Metabolomics and Bioanalysis (CEMBIO), Facultad de Farmacia, Universidad San Pablo-CEU. ${ }^{(2)}$ Facultad de Farmacia, Universidad de Barcelona, CIBERobn, IBUB, Barcelona, Spain. ${ }^{(3)}$ Departamento de Metabolismo y Nutrición, Instituto de Ciencia y Tecnología de Alimentos y Nutrición (ICTAN/CSIC), C/ José Antonio Novais, 10, Ciudad Universitaria, 28040 Madrid, Spain. ${ }^{(4)}$ CQS Lab, Madrid, Spain.

Abbreviations: AOPP, advanced oxidation protein products; BGE, background electrolyte; Gpx1, glutathione peroxidase; GR, glutathione reductase; GSH, reduced glutathione; GSSG, oxidized glutathione; HDAC3, histone deacetylase 3; HO-1, heme oxygenase-1; MDA, malondialdehyde; NEFA, non-esterified fatty acid; NOQ1, NAD(P)H quinone oxidoreductase 1; Nrf2, Nuclear factor-erythroid 2-related factor 2; ROS, reactive oxygen species; SOD, superoxide dismutase; TBAR, thiobarbituric acid reactive substances; UCP2, uncoupling protein 2; XBP1u, unspliced X-box-binding protein 1.

Key words: Fructose; pregnancy; oxidative stress; heme oxygenase-1; placenta.

Corresponding author:

Carlos Bocos; Facultad de Farmacia; Universidad San Pablo-CEU; Urbanización Montepríncipe; 28668 Boadilla del Monte, Madrid, Spain. Phone: +34-91-372.47.98; FAX: +34-91-351.04.96; E-mail: carbocos@,ceu.es 
Fructose and fetal oxidative stress

\begin{abstract}
Scope:

One of the features of metabolic syndrome caused by liquid fructose intake is an impairment of redox status. We have investigated whether maternal fructose ingestion modifies the redox status in pregnant rats and their fetuses.

Methods and results:

Fructose $(10 \% \mathrm{wt} / \mathrm{vol})$ in the drinking water of rats throughout gestation, leads to maternal hepatic oxidative stress. However, this change was also observed in glucose-fed rats and, in fact, both carbohydrates produced a decrease in antioxidant enzyme activity. Surprisingly, mothers fed carbohydrates displayed low plasma lipid oxidation. In contrast, fetuses from fructose-fed mothers showed elevated levels of plasma lipoperoxides versus fetuses from control or glucose-fed mothers. Interestingly, a clearly augmented oxidative stress was observed in placenta of fructose-fed mothers, accompanied by a lower expression of the transcription factor Nuclear factor-erythroid 2-related factor-2 (Nrf2) and its target gene, heme oxygenase-1 (HO-1), a potent antioxidant molecule. Moreover, histone deacetylase 3 (HDAC3) which has been proposed to upregulate HO-1 expression by stabilizing Nrf2, exhibited a diminished expression in placenta of fructose-supplemented mothers.

Conclusions:

Maternal fructose intake provoked an imbalanced redox status in placenta and a clear diminution of HO-1 expression, which could be responsible for the augmented oxidative stress found in their fetuses.
\end{abstract}




\section{Introduction}

In the last few decades, obesity, metabolic syndrome and diabetes have escalated to epidemic proportions in many countries worldwide. Fructose, present in added sugars such as sucrose and high fructose corn syrup, has been linked to obesity and metabolic syndrome [1]. Experimental studies have shown that fructose can induce leptin resistance and features of metabolic syndrome in rats, whereas glucose intake does not [1]. Thus, diets incorporating $10 \% \mathrm{wt} / \mathrm{vol}$ of fructose in drinking water induce hypertriglyceridemia and fatty liver [2]. Clinical studies also support fructose as a cause of metabolic syndrome [3,4]. In contrast, several recent trials using fructose and other carbohydrates have instead reported that no sugar has more deleterious effects than others [5,6]. Therefore, debate over the role of fructose in mediating metabolic syndrome and related diseases remains open.

Fructose is differentially metabolised in comparison to glucose and provokes an intracellular ATP depletion that generates uric acid and therefore, hyperuricemia [7]. Uric acid works as an antioxidant in the extracellular environment, but it can induce oxidative stress inside cells [1]. In fact, it has been proposed that uric acid induces hepatic steatosis by generation of mitochondrial oxidative stress [8]. On the other hand, it has been demonstrated that fructose is very reactive, even more so than glucose, and is able to participate in glycosilation reactions which generate free radicals [9]. Whether or no this is due to a direct effect of fructose or an indirect one mediated by the uric acid generated during fructosemetabolism, it is widely accepted that fructose-rich syrups promote an increase of oxidative stress. In fact, as has been previously demonstrated, short-term administration of fructose to male rats induces changes in many oxidative stress markers and also in the antioxidant system $[10,11,12]$ both in liver and adipose tissue.

On the other hand, several experimental and epidemiological studies have demonstrated that metabolic events during pre- and postnatal development markedly modulate metabolic disease risks in later life [13]. Among them, feeding conditions are likely to constitute one of the most influential parameters on the health of the adult [14]. Thus, diet manipulation in mothers during critical developmental periods (such as gestation and/or the early postnatal) can permanently modify the physiology and metabolism of their offspring $[15,16]$. This phenomenon is called early nutritional or metabolic programming of adult health [13]. 
Therefore, we and others have speculated as to whether fructose administration during gestation could cause changes in the perinatal development of fetuses and after, long-standing consequences in adult metabolism. Thus, we have previously found that fetuses from fructosefed mothers displayed impaired transduction of the leptin signal and hepatic steatosis, and these findings were not observed in glucose-fed rats [17]. Furthermore, in a long-term study [18], we reported that maternal fructose intake produced adverse effects (impaired insulin signal transduction, hyperinsulinemia, and hypoadiponectinemia), which could only have originated during intrauterine development since fructose administration was strictly confined to the pregnancy period. Recently, Clayton et al (2015) have confirmed that early life exposure to fructose alters maternal and perinatal hepatic gene expression [16].

Moreover, since fructose intake has also been confirmed to alter the homeostasis redox [10-12], it should not be surprising if fructose administration during gestation is able to induce oxidative stress in perinatal and the later life of progeny. In accordance with this, Ching et al (2011) showed that a high-fructose diet during gestation and lactation compromises hepatic antioxidant status in adult male offspring [19]. In addition, we have also found an increase in plasma levels of protein oxidation products in male, but not female, progeny from fructose-fed dams [9]. However, in order to avoid all these adverse effects, placenta is supposed to protect the fetus against oxygen toxicity. Thus, it has been demonstrated that placental tissue suppresses lipoperoxide formation in the late gestational period and lowers the concentration of lipoperoxides in the blood. In fact, although the concentration of lipoperoxides in maternal blood increases as gestation progresses, the concentration in the cord blood is much lower than that in maternal blood [20] and, accordingly, a gradual suppression of lipoperoxide content in fetal liver is also observed as gestation progresses [21]. However, Vickers et al (2011) showed remarkably that maternal fructose consumption leads to manifest changes in placental growth [22]. Therefore, it should be worth investigating whether fructose is able to produce changes in the placenta which could cause an imbalance in the redox status of the fetus.

Accordingly, the current report is a follow-up study to investigate the effects of fructose intake $(10 \% \mathrm{wt} / \mathrm{vol})$ throughout gestation on oxidative stress both in mothers and their fetuses. In contrast to others $[19,22]$, our model of maternal liquid fructose intake is confined to the prenatal stage and compares the effects of fructose- versus glucose-supplementation. First of all, to check the oxidative stress status in both the mothers and their fetuses, lipid peroxidation as TBARS and protein oxidation as carbonyls of proteins were measured in plasma, adipose tissue, liver and 
placenta. Secondly, the activity and mRNA expression of scavenging enzymes (superoxide dismutase, SOD; catalase; glutathione peroxidase, Gpx1; and glutathione reductase, GR) as well as the concentrations of non-enzymatic antioxidants (glutathione) or pro-oxidants (uric acid) were determined in maternal and fetal liver and placenta. And finally, in order to elucidate the mechanism of action of fructose-induced changes in oxidative stress, the expression of potent endogenous antioxidant genes, such as hemeoxygenase-1 (HO-1) and $\mathrm{NAD}(\mathrm{P}) \mathrm{H}$ quinone oxidoreductase 1 (NOQ1), and several components of the signaling cascade which regulate their gene expression, were also determined.

\section{Materials and methods}

\subsection{Animals and experimental design}

An animal model of maternal liquid fructose intake was developed as previously described [17]. Briefly, female Sprague-Dawley rats weighing 200-220 g were fed ad libitum standard rat chow (B\&K Universal, Barcelona, Spain) and housed under controlled light and temperature conditions (12-h light-dark cycle; $\left.22 \pm 1^{\circ} \mathrm{C}\right)$. The experimental protocol was approved by the Animal Research Committee of the University San Pablo-CEU, Madrid, Spain. Animals were mated, and day 0 of pregnancy was determined by the appearance of spermatozoids in vaginal smears. Then, the animals were randomly separated into a control group (seven rats), a fructose-supplemented group (Fructose; seven rats), and a glucosesupplemented group (Glucose; six rats). Fructose and glucose were supplied as a 10\% (wt/vol) solution in drinking water throughout gestation. Control animals received no supplementary sugar.

On the morning of the $21^{\text {st }}$ day of pregnancy, rats were decapitated and blood collected using tubes containing $\mathrm{Na}_{2}$-EDTA. Liver and lumbar adipose tissue were immediately removed, placed in liquid nitrogen and kept at $-80{ }^{\circ} \mathrm{C}$ until analysis. The conceptus was dissected and, after being weighed, fetuses were counted and weighed. Placentas were also obtained, weighted, frozen and those coming from the same litter were pooled. Fetuses (without being separated by gender) were decapitated, and blood from all pups of the same mother was collected and pooled into receptacles containing $\mathrm{Na}_{2}$-EDTA for immediate separation of plasma at $4{ }^{\circ} \mathrm{C}$. The livers of the fetuses were obtained, and those coming from the same mother were pooled and placed in liquid nitrogen to be stored at $-80^{\circ} \mathrm{C}$ until processed for further analysis.

\subsection{Determinations}


One hundred milligrams of frozen liver (or placenta), or $200 \mathrm{mg}$ of frozen adipose tissue were homogeneized into $0.25 \mathrm{M}$ Tris- $\mathrm{HCl}, 0.2 \mathrm{M}$ sucrose, and $5 \mathrm{mM}$ dithiothreitol (DTT) $\mathrm{pH} 7.4$ buffer. Plasma aliquots or tissue homogenates were used to determine the oxidative stress state. The concentration of malondialdehyde (MDA) was measured as a marker of lipid peroxidation using the method previously described [23], by measuring the fluorescence of MDA-thiobarbituric acid (TBA) complexes at $515 \mathrm{~nm} / 553 \mathrm{~nm}$ excitation/emission wavelengths. As a protein oxidative stress biomarker, carbonyls of protein content were measured using the method previously described [24]. Uric acid concentration was determined in plasma or homogenates using a commercial kit (Spinreact, Spain). Further, where indicated, the advanced oxidation protein products (AOPP) were also determined using homogenates prepared into Tris $50 \mathrm{mM} \mathrm{pH} 7.4$ buffer and the spectrophotometric technique previously described [25]. The AOPP concentrations were expressed as $\mu \mathrm{mol} / \mathrm{L}$ of chloramine-T equivalents.

Samples of tissue were also used to determine the ratio between the contents of reduced glutathione (GSH) and oxidized glutathione (GSSG), using capillary electrophoresis coupled to UV-DAD and following the method previously reported [26] for liver and, with some modifications, for placenta. Namely, $50 \mathrm{mg}$ of placenta were homogenized with a Tissue Lyser LT (Qiagen, Valencia, CA, USA) in cold purified water, $134 \mathrm{mM}$ EDTA, and $100 \mathrm{mM}$ N-ethylmaleimide (NEM) (1:1:4) buffer solution. After centrifugation, $400 \mu \mathrm{L}$ of supernatant were deproteinized by ultrafiltration, using a Microcon-30 column (Millipore, Billerica, MA, USA) and centrifugation at $36,220 \mathrm{xg}$ for $10 \mathrm{~min}$ at $4^{\circ} \mathrm{C}$. Finally, for placenta, the background electrolyte (BGE) was prepared with $0.4 \mathrm{M} \mathrm{H}_{3} \mathrm{BO}_{3} \mathrm{pH} 8.0$. A voltage of $27 \mathrm{kV}$ was applied and the current generated was $62 \mu \mathrm{A}$. The injection was by pressure at 33 mbar for $40 \mathrm{~s}$.

\subsection{Total RNA preparation and analysis}

Total RNA was isolated from liver or placenta using Ribopure (Ambion Inc., USA). RNA was prepared either from the liver of individual animals or from pools of the same litter for fetal livers or placentas. The 260/280 absorption ratio of all samples was between 1.8 and 2.0. Total RNA was subjected to DNase I treatment using Turbo DNA-free (Ambion Inc., USA), and RNA integrity was confirmed by agarose gel electrophoresis. Genomic DNA contamination was discarded by PCR using primers for ribosomal protein S29 (Rps29), resulting in a negative reaction. After, cDNA was synthesized by oligo(dT)-primed reverse 
transcription with Superscript II (Invitrogen, USA). qPCRs were carried out using a Light Cycler 1.5 (Roche, Germany). The reaction solution was performed in a volume of $20 \mu$, containing 10 pmol of both forward and reverse primers, 10x SYBR Premix Ex Taq (Takara Bio Inc., Japan) and appropriate nanograms of the cDNA stock. Rps29 was used as a reference gene for qPCR. The sense and antisense primers sequences were: 5'GAAGGCAAGATGGGTCACCAGCAGC-3' and 5'CAGGGTAGACAGTTGGTTTCATTGGG-3' for Rps29 (BC058150). The rest of the primer sequences were obtained either from Atlas RT-PCR Primer Sequences (Clontech, CA, USA) or designed using Primer3 software (University of Massachusetts Medical School, Worcester, Massachusetts, USA) [27]. Samples were analyzed in duplicate on each assay. Amplification of non-specific targets was discarded using the melting curve analysis method for each amplicon. qPCR efficiency and linearity were assessed by optimization of standard curves for each target. The transcription was quantified with Light Cycler Software 4.05 (Roche, Germany) using the efficiency correction method [28].

\subsection{Determination of antioxidant enzymes activity}

The activity of the enzyme glutathione reductase was determined by following the oxidation of NADPH to $\mathrm{NADP}^{+}$cofactor for the reduction of oxidized glutathione, which is proportional to the activity thereof [29]. To measure the activity of glutathione peroxidase, the protocol previously described was used [30]. Catalase activity was studied by the $\mathrm{H}_{2} \mathrm{O}_{2}$ decomposition caused by the activity of that enzyme [31]. This was done by recording the absorbance maximum of $\mathrm{H}_{2} \mathrm{O}_{2}$ to $240 \mathrm{~nm}$. Finally, the activity of superoxide dismutase (SOD) was measured using a commercial kit (Spinreact, Spain).

\subsection{Western blot analysis}

Thirty micrograms of different protein fractions from rat tissues were subjected to $10 \%$ SDS-polyacrylamide gel electrophoresis. Proteins were transferred to Immobilon polyvinylidene difluoride transfer membranes (Millipore, Billerica, MA, USA) and blocked for $1 \mathrm{~h}$ at room temperature with 5\% non-fat milk solution in $0.1 \%$ Tween-20-Tris-buffered saline (TBS). Membranes were then incubated overnight with the primary antibody raised against Nrf2 or HO-1, in $0.1 \%$ Tween-20-TBS with $5 \%$ bovine serum albumin (BSA) at $4{ }^{\circ} \mathrm{C}$. Detection was achieved using the enhanced chemiluminescence (ECL) kit for horseradish peroxidase (HRP) (Amersham GE Healthcare Europe GmbH, Barcelona, Spain). To confirm 
the uniformity of protein loading, the blots were incubated with $\beta$-actin antibody (SigmaAldrich, St. Louis, MO, USA) as a control. The size of detected proteins was estimated using protein molecular-mass standards (Invitrogen, Life Technologies). Primary antibodies for HO-1 and Nrf2 were obtained from Santa Cruz Biotechnologies (Dallas, TX, USA).

\subsection{Statistical analysis}

Results were expressed as means \pm S.E. Treatment effects were analyzed by one-way analysis of variance (ANOVA). When treatment effects were significantly different $(\mathrm{P}<0.05)$, means were tested by Tukey multiple range test, using the computer program SPSS (version 15). When the variance was not homogeneous, a post hoc Tamhane test was performed.

\section{Results}

\subsection{Ingestion of a $10 \% \mathrm{w} / \mathrm{v}$ fructose solution throughout gestation increases oxidative stress in liver but decreases it in plasma of pregnant rats}

We have previously reported that maternal fructose intake during gestation did not change maternal body weight by the end of the gestation, after 21 days of fructose administration [17]. The total amount of ingested energy did not differ between fructose-supplemented and control rats [17]. Interestingly, and unlike most of the other studies, one group of fed glucose mothers was studied in parallel. Neither fructose-fed nor glucose-fed pregnant rats showed alterations in the litter size, body weight of their fetuses [17], nor in placental weight (data not shown). No differences were seen among the three groups for either glycemia or insulinemia $[17]$.

Surprisingly, plasma MDA, which would indicate lipid oxidation, was significantly diminished in the carbohydrate-fed mothers (Figure 1A). Moreover, this effect was observed in spite of there being a higher amount of substrate to be oxidized given that fructose-fed pregnant rats were hypertriglyceridemic compared to control rats [17]. In contrast, hepatic MDA was augmented both in fructose-fed and in glucose-fed mothers in comparison to the control pregnant rats (Figure 1B). Curiously, MDA values found in lumbar adipose tissue showed a similar pattern to those observed in plasma. That is, adipose MDA concentration was lower in the carbohydrate-fed pregnant rats in comparison to the control mothers (Figure 1C) ( $\mathrm{x} 0.49$ and $\mathrm{x} 0.61$ fold reduction for fructose and glucose groups, respectively, versus the control group), although the effect did not become significant. The lower oxidative stress in adipose tissue was confirmed since both AOPP and uric acid levels were also diminished in 
carbohydrate-fed mothers. Thus, AOPP levels, which are an indicator of protein oxidation, were reduced in fructose- and glucose-fed mothers in comparison to the control pregnant rats $(0.40 \pm 0.04 ; 0.34 \pm 0.01$ and $0.26 \pm 0.05 \mu \mathrm{mol}$ of chloramine- $\mathrm{T}$ equivalents $/ \mathrm{g}$ of tissue, for control, fructose- and glucose-fed mothers, respectively). Also, uric acid concentration in adipose tissue was diminished $(8.6 \pm 0.5 ; 6.2 \pm 0.4$ and $5.9 \pm 0.8 \mu \mathrm{g} / \mathrm{mg}$ of protein, for control, fructose- and glucose-fed mothers, respectively; $\mathrm{P}<0.05$, fructose and glucose versus control groups).

Regarding other plasma oxidative stress markers, the levels of protein carbonyls were similar among the three groups and uricemia, as expected, was significantly augmented in fructose-fed mothers in comparison to the control and glucose-fed pregnant rats (Table 1). On the other hand, hepatic protein carbonyls and uric acid concentration presented the same profile (Table 1) for the three groups as the one observed for liver MDA in Figure 1B. To further investigate the mechanism behind this carbohydrate-induced pro-oxidant effect, we determined several components of the antioxidant system in the pregnant livers. The GSH/GSSG ratio tended to be augmented in carbohydrate-fed pregnant rats, although it only became (marginally) significant $(\mathrm{P}=0.064)$ for the fructose group, in comparison to the control rats (Table 1). The reason for these findings was not an increase in the levels of GSH, since they were similar for the three groups $(5.7 \pm 0.3 ; 6.4 \pm 0.5$ and $5.9 \pm 0.7 \mu \mathrm{M} / \mathrm{g}$ of tissue, for control, fructose- and glucose-fed mothers, respectively), but a diminution in the levels of GSSG $(0.55 \pm 0.05 ; 0.27 \pm 0.03$ and $0.29 \pm 0.04 \mu \mathrm{M} / \mathrm{g}$ of tissue, for control, fructose- and glucose-fed mothers, respectively; $\mathrm{P}<0.05$, fructose and glucose versus control). According to this, Gpx1 activity (Table 1$)$ and mRNA expression $(1.25 \pm 0.25 ; 1.07 \pm 0.22$ and $1.01 \pm$ 0.19 arbitrary units (a.u.), for control, fructose and glucose-fed mothers, respectively) were decreased in the liver of carbohydrate-fed mothers. Catalase and manganese-SOD (SOD2) activities showed no difference between the three groups. However, copper/zinc-superoxide SOD (SOD1) tended to be diminished in fructose-fed mothers in comparison to the control and glucose-fed pregnant rats, although this did not become significant (Table 1). The SOD1 mRNA gene expression did not show any differences among the three experimental groups (data not shown).

\subsection{Ingestion of a $10 \% \mathrm{w} / \mathrm{v}$ fructose solution throughout gestation increases oxidative stress in placenta and fetal liver and plasma}


One of the most important aims of the present work was to determine whether the ingestion of a fructose solution $(10 \% \mathrm{w} / \mathrm{v})$ by pregnant rats throughout gestation would affect the oxidative stress of their fetuses. Interestingly, fetuses from fructose-fed mothers presented, in contrast to the findings observed in their mothers, higher plasma MDA in comparison to fetuses from control and glucose-fed mothers $(5.44 \pm 0.21,6.56 \pm 0.45$, and $5.27 \pm 0.36 \mu \mathrm{M}$, for control, fructose-fed and glucose-fed mothers, respectively; $\mathrm{P}=0.058$, fructose versus glucose group), becoming significant when expressed as nmol of MDA/mg of triglycerides (Figure 2A). Coincident with this finding, hepatic MDA was also augmented in fetuses from fructose-fed mothers (Figure 2B). Curiously, placental MDA concentration was also higher in the fructose-fed pregnant rats versus those values found in control and glucose-fed mothers (Figure 2C).

In contrast to the higher oxidation observed for lipids in fetal plasma from fructose-fed pregnant rats (Figure 2A), both plasma protein carbonyls and uricemia were similar in fetuses from fructose-fed mothers versus fetuses of the other two groups (Table 2). On the other hand, hepatic carbonyls and uric acid concentration were augmented in fetuses from fructosefed in comparison to the fetuses from glucose-fed and control pregnant rats (Table 2), becoming significant only for the uric acid and (marginally) significant for the protein oxidation ( $\mathrm{P}<0.08$, fructose versus control group). To further investigate the mechanism behind this fructose-induced pro-oxidant effect, we found that the GSH/GSSG ratio, catalase, Gpx1 and SOD2 activities did not show any differences between the three groups. However, GR and, principally, SOD1 activities were significantly augmented in fetuses from fructosefed mothers in comparison to those from control and glucose-fed pregnant rats (Table 2). The fetal SOD1 mRNA gene expression, instead, did not show any differences among the three experimental groups (data not shown).

Interestingly, placental MDA was augmented in fructose-fed mothers (Figure 2C). Likewise, the concentration of protein carbonyls did parallel the MDA content, this being higher in the fructose group versus the other two groups (Table 2). However, the uric acid content in placenta was similar for the three experimental groups (Table 2). On the other hand, we found that the GSH/GSSG ratio, Gpx1, GR, and SOD1 activities did not show any differences among the three groups. As well, catalase activity showed no differences between control and fructose group, although it was different for the glucose group. However, SOD2 activity was significantly augmented in placenta from fructose-fed mothers in comparison to the control and glucose-fed pregnant rats (Table 2). Further, placental SOD2 mRNA gene 
expression mirrored the findings observed for the SOD2 activity $(0.261 \pm 0.044 ; 0.396 \pm$ 0.024 and $0.247 \pm 0.030$ a.u., for control, fructose- and glucose-fed mothers, respectively; $\mathrm{P}<$ 0.05 , fructose versus control and glucose groups).

\subsection{Fructose decreases heme oxygenase-1 (HO-1) expression in maternal liver and placenta}

Heme oxigenase-1 (HO-1) is a potent endogenous antioxidant gene, playing a key role in decreasing oxidative stress [32]. Moreover, both murine hepatocytes treated with fructose and adipose tissue from mice fed a high-fructose diet displayed a decrease in HO-1 mRNA levels [32,33]. As shown in Figure 3A, not only fructose-fed mothers but also glucose-fed mothers showed a marked decrease in hepatic HO-1 mRNA expression in comparison to the control rats. Unexpectedly, fetal liver HO-1 mRNA gene expression did not display any differences between the three experimental groups (Figure 3B). Interestingly, placenta displayed a fructose-specific drop in HO-1 mRNA gene expression, this being significantly different in comparison to control and glucose-fed mothers (Figure 3C). In addition, since HO-1 is a target gene of the transcription factor Nrf2 (Nuclear factor-erythroid 2-related factor 2) [34], we also determined the gene expression of another well-known Nrf2- target gene, that is, $\mathrm{NAD}(\mathrm{P}) \mathrm{H}$ quinone oxidoreductase 1 (NOQ1). As shown in Table 3, NOQ1 mRNA gene expression was clearly diminished in the liver of carbohydrate-fed mothers, not affected in the liver of fetuses independently of the mother's diet and specifically decreased in placenta from fructose-fed mothers.

Recently, it has been reported that the interaction between unspliced X-box-binding protein 1 (XBP1u) and histone deacetylase 3 (HDAC3) modulates oxidative stress by stabilizing Nrf2 transcription factor and regulating HO-1 expression [35]. Thus, although both fructose and glucose diets increased HDAC3 mRNA expression in maternal liver $(+15 \%$ and $+16 \%$ versus control, respectively), XBP1u mRNA levels were significantly reduced in carbohydrate-fed mothers in comparison to the control pregnant rats $(-30 \%$ and $-43 \%$, for fructose and glucose versus control groups) (Table 3), in consonance to the decrease found in the HO-1 expression of these rats (Figure 3A). In accordance with the lack of effect observed in fetal liver HO-1 expression (Figure 3B), both HDAC3 and XBP1u mRNA levels were not affected by maternal carbohydrate intake (Table 3) in fetal liver. However, and more notably, although XBP1u placental expression did not display any differences among the three groups, HDAC3 mRNA levels were clearly reduced in placenta from fructose-fed mothers (Table 3) 
versus the other two groups, coincident with the decrease observed in the HO-1 gene expression (Figure 3C).

Finally, in order to corroborate the findings observed in mRNA expression, HO-1 and Nrf2 protein levels were also measured. Thus, although Nrf2 tended to be diminished in liver of carbohydrate-fed mothers, only HO-1 protein levels were decreased, although not significantly, in fructose-fed mothers (Supporting Information Table 1). As expected, in fetal liver, neither HO-1 nor Nrf2 presented significant differences between the three experimental groups. Interestingly, as shown in Figure 4, Nrf2 and HO-1 protein levels were significantly reduced in placenta of fructose-fed mothers.

\section{Discussion}

Fructose, present in added sugars such as sucrose and high fructose corn syrup, has been linked to obesity and metabolic syndrome [1]. Further, it is well known that fructose-rich syrups promote oxidative stress [10-12]. Therefore, oxidative stress could be the missing link between fructose consumption, obesity and metabolic syndrome. However, consumption of those beverages and fruit juices is allowed during gestation. Moreover, it is well known that placenta must combat oxidative stress during gestation to protect the fetus against toxicity associated with reactive oxygen species (ROS). Toxicity of ROS is due to their ability to modify macromolecules such as proteins, lipids and DNA thereby destroying the integrity of the cells. Furthermore, most of the ROS are able to cross the placenta and reach the fetus [21], and placental oxidative stress has been reported as a potential factor in the pathogenesis of pre-eclampsia, early pregnancy failure and fetal malformations [21,36]. In spite of all these findings, the number of studies based on the effects of fructose in the redox status during the perinatal period is scarce. Therefore, the current report is a follow-up study to investigate the effects of fructose intake $(10 \% \mathrm{wt} / \mathrm{vol})$ throughout gestation in the redox status of mothers, their fetuses and placentas.

Thus, fructose induced oxidative stress in maternal liver. However, this increase was also found in glucose-fed pregnant rats. These findings reinforce the importance of studying the effects of fructose in comparison to those of glucose-supplementation, in order to be sure that the effects provoked by fructose are specific to this carbohydrate. Coincident to this augmentation in hepatic oxidative stress, an increase in hepatic uric acid content was found. Lanaspa et al (2012) had already shown that many of the fructose-induced effects observed in the liver (lipid deposition, oxidative stress) are mediated by uric acid [8]. Related to this, 
carbohydrate-fed mothers had showed a clear accumulation of triglycerides in the liver, in our previous study [17]. Moreover, the expression of uncoupling protein 2 (UCP2), a molecule with the capacity to attenuate both mitochondrial ROS production and oxidative damage [37], was also reduced in carbohydrate-supplemented mothers [17].

On the other hand, a deficient hepatic antioxidant defence system was observed. Thus, Gpx1 activity was decreased in glucose- and fructose-mothers versus control rats. This finding could explain the augmented GSH/GSSG ratio found in the liver of carbohydratesupplemented mothers. Since GR activity was not affected by the maternal diet, the diminution observed in the hepatic oxidized glutathione (GSSG) content in carbohydrate-fed mothers could be due to their decreased Gpx1 activity. According to this, it has also been shown that, upon oxidative stress, a decrease in the GSSG content could eventually result in a decrease in the antioxidant potential of the cell [38]. Further, fructose has been demonstrated to be able to reduce HO-1 expression in both liver and adipose tissue and, accordingly, increase oxidative stress [32,33]. However, in our model, not only fructose-fed, but also glucose-fed, mothers displayed a clear reduction in liver HO-1 expression in comparison to the control rats. Like HO-1, NOQ1 is a Nrf2 target gene with antioxidant properties [34]. Likewise, NOQ1 gene expression was diminished by carbohydrate ingestion throughout gestation, which corroborates the participation of that transcription factor (Nrf2). In order to elucidate the action mechanism, we have studied XBP1u and HDAC3 gene expression since it was demonstrated that unspliced XBP1 and HDAC3 are involved in the formation of a complex that stabilizes Nrf2 and, accordingly, regulates HO-1 mRNA expression [35]. Thus, although carbohydrate-fed mothers showed an increase in HDAC3 expression, the drop in the $\mathrm{XBP} 1 \mathrm{u}$ expression was so highly pronounced in those animals that it could be compromising the formation of the XBP1u/HDAC3 complex, which, in turn, would affect the Nrf2 stabilization and its transcriptional activity. In fact, protein levels of Nrf2 were diminished in carbohydrate-fed pregnant rats.

Unexpectedly, fructose- and glucose-fed mothers showed a clear diminution in plasma oxidative stress. This situation appeared to be due to a decreased lipid oxidation. It is wellknown that adipose lipolytic activity is increased in late pregnancy $[39,40]$ providing nonesterified fatty acids to the maternal circulation. Then, a great amount of the lipids present in blood would come from this active lipolysis and, therefore, it is not surprising that the low content of lipid peroxidation products found in lumbar adipose tissue of carbohydrate-fed mothers mirrored that found in plasma. An estrogen protection against fructose-induced 
oxidation cannot be discarded [41], since the pregnant rats present higher plasma estrogen levels than rats in a non-pregnant condition [42].

Interestingly, fetuses from fructose-fed mothers showed higher plasma lipid peroxidation than pups from control and glucose-fed dams. Further, fetuses from fructose-fed pregnant rats presented a significantly higher accumulation of lipid peroxidation products in their livers than those observed in fetuses from dams fed glucose or control rats, with a slight rise in protein oxidation. Consistent with these results, the levels of hepatic methylglyoxal, an inducer of oxidative stress and protein carbonylation [43], were clearly augmented in fetuses from fructose-fed mothers (unpublished results). The increase observed in lipid peroxidation of the fetal liver was coincident with an increase in the uric acid content. As mentioned above, it has been previously shown that lipid deposition and oxidative stress could be mediated by uric acid [8]. In our previous study, fetuses from fructose-fed mothers displayed a clear accumulation of triglycerides in the liver and diminished expression of UCP2 [17]. Nevertheless, an increased antioxidant defence system was detected as a compensatory mechanism in response to the lipid peroxidation observed in fetuses from fructose-fed mothers. Thus, both GR and SOD1 activities were specifically increased in this group. However, neither HO-1 nor NOQ1 gene expression showed differences among the three experimental groups. Coincident to this lack of effect, neither XBP1u and HDAC3 mRNA, nor Nrf2 and HO-1 protein expression displayed changes in response to the maternal diet. Therefore, it could be assumed that the high hepatic lipid peroxidation found in fetuses from fructose-fed mothers is mainly due to the oxidation state of the lipids arriving to the liver from the circulation, rather than an augmented oxidation inside the organ.

On the other hand, it is known that placenta allows fatty acids to reach the fetus from maternal circulation in order to be used for triglyceride synthesis in the fetal liver [44]. Interestingly, placenta from fructose-supplemented mothers presented a clear oxidative stress in comparison to the other two groups, measured as both lipid and protein oxidation markers. In order to compensate this oxidative damage, both gene expression and activity of SOD2 were clearly augmented in the fructose-fed group. However, the potent antioxidant gene HO-1 presented a marked lower expression in placenta of fructose-fed mothers in comparison to the other pregnant rats. Coincident to this finding, NOQ1 gene expression was also reduced. This is a relevant finding since, although it has been previously proposed that fructose inhibits HO1 mRNA expression in liver and adipose tissue [32,33], this is the first time the way in which fructose is able to down-regulate HO-1 gene expression in placenta has been demonstrated. 
Importantly, in our model, the inhibitory fructose-induced effect was also mediated by a glucose-diet in liver, but not in placenta, suggesting a different mechanism of action. In fact, whereas in liver, XBP1u is the component of the complex that was diminished, in placenta, it is the HDAC3 molecule whose expression is down-regulated by fructose. This finding reinforces HDAC3 as a key component in the complex regulating Nrf2-target gene expression [35]. Coincident to these effects, the transcription factor Nrf2 and its target gene, HO-1, exhibited a drop in their protein levels exclusively in the placenta of fructose-fed mothers. Therefore, the fructose-induced reduction observed in HO-1 and NOQ1 perfectly would explain the increase in oxidative stress found in the placenta of this experimental group.

Thus, in our model, we propose that low placental HO-1 would be unable to counteract the fructose-induced oxidative stress in placenta in such a way that lipids from the maternal plasmatic side (poorly-oxidized) arriving at the fetus (highly-oxidized) would be being oxidized while they were crossing the placenta and thus, generating a redox state imbalance in fetuses from fructose-fed mothers [21]. Nonetheless, some other mechanisms could also be involved. Thus, it has been recently proposed that an excess of maternal fructose consumption alters placental function via a xanthine oxidase/uric acid-dependent mechanism [45]. However, Vickers et al (2011) showed that the impairment of placental growth and function could be due to fructose-induced effects on placental transporters, growth factors, glucocorticoid sensitivity and placental leptin transfer [22]. In fact, it has been shown that fructose can induce a deranged antioxidant system by modulating glucocorticoid signalling [46]. Moreover, the decidual cells support pregnancy by producing hormones, cytokines, and antioxidants, and it has been shown that maternal fructose consumption impairs endometrial decidualization in mice [47]. On the other hand, accumulation of bile acids in maternal serum has been demonstrated to produce placental oxidative stress [48], and maternal fructose intake reduces maternal cholesterolemia [45].

Placental HO-1 has a protective role due to its antiinflammatory, antiapoptotic, antioxidative and antiproliferative actions, and it is a major regulator of immune homeostasis [49]. Thus, HO-1 and its byproducts may prevent or treat pregnancy complications, prematurity, and adverse neonatal outcomes. Therefore, the situation observed in our study, where fructose intake in pregnancy down-regulates placental HO-1, may be relevant since it has been demonstrated that maternal sugar consumption is associated with an increased risk of preeclampsia [50]. Nevertheless, our study has some limitations that could be addressed in the future, apart from difficulties in extrapolating results from experimental animals to 
humans. These are: (1) We have suggested that placenta is responsible for the contrary findings found in maternal plasma lipoperoxidation (low) and in their fetuses (high). However, we have no information about substrate availability and transport from placenta to fetus. (2) We used fructose only during pregnancy. However, Kendig et al (2015) observed differences between providing sucrose only when the rats were already pregnant or commencing access to sucrose several weeks prior to mating [51]. (3) Fetuses and placentas were harvested without being separated by gender, and sex differences exist in oxidative stress and response to nutrients, as reported previously [22,52]. (4) We have used simple sugars solutions instead of sucrose (table sugar) or high fructose corn syrup (HFCS), and it is known that fructose absorption is improved by the presence of glucose. Moreover, in our society, fructose and glucose are rarely taken separately. However, the concentration used here $(10 \% \mathrm{w} / \mathrm{v})$ is very close to that of sugar-sweetened beverages and the amount of total calories obtained from simple sugars in our study (25\% for the fructose-group; $35 \%$ for the glucose-group) was similar to the daily energy intake from simple sugars observed in heavy consumers of sweetened beverages in human populations (20-25\%).

Finally, the present findings can help us to further understand how the action mechanism of fructose induces some features of the metabolic syndrome. Rebollo et al (2014) proposed that the fructose-induced inhibition of fatty acid oxidation and the increase of lipid synthesis in the liver occur by a mechanism that involves a decrease of sirtuin 1 (Sirt1) function [53]. More recently, Sodhi et al (2015) showed that HO-1 and oxidative stress were upstream of Sirt1 in the fructose-activated pathway to induce hepatic lipid deposition [32]. Furthermore, Martin et al (2014) demonstrated that XBP1u and HDAC3 participate, forming a complex, in the regulation of HO-1 expression antagonizing reactive oxygen species (ROS) generation [35]. Here, we have demonstrated that fructose affects XBP1u and HDAC3 mRNA expression, inhibiting HO-1 expression and, accordingly, increasing the oxidative stress. Therefore, our findings would reinforce the hypothesis that the imbalance in the redox status produced by fructose is one of the most important and possibly the first alteration in the plethora of detrimental effects that fructose provokes [32].

\section{Acknowledgements}

The authors thank Jose M. Garrido for his help in handling the rats, and Brian Crilly for his editorial help. This work was supported by grants from the Instituto de Salud Carlos III- 
Subdirección General de Evaluación y Fomento de la Investigación (PI-09/02192), European Community FEDER funds, as well as the Ayuda a Grupo en Consolidación Universidad San Pablo-CEU and Banco de Santander (USP-BS-PCON02/2015). Silvia Rodrigo is a FUSP-CEU fellowship. C.Bo. and J.J.A-M conceived and designed the study.

S.Ro., L.R., P.O. and M.I.P. performed the experiments. M.I.P. analyzed the data. A.G., C.Ba., S.Ra, and L.G. contributed reagents/materials/analysis tools for oxidative stress studies. S.Ro, N.R. and J.C.L. conducted the protein analysis. C.Bo. wrote the paper. None of the authors has any conflicts of interest to report.

\section{References}

1. Johnson, R.J., Perez-Pozo, S.E., Sautin, Y.Y., Manitius, J. et al., Hypothesis: could excessive fructose intake and uric acid cause type 2 diabetes? Endocr. Rev. 2009, 30(1), 96-116.

2. Roglans, N., Sanguino, E., Peris, C., Alegret, M. et al., Atorvastatin treatment induced peroxisome proliferator-activated receptor alpha expression and decreased plasma nonesterified fatty acids and liver triglyceride in fructose-fed rats. J. Pharmacol. Exp. Ther. 2002, 302(1), 232-239.

3. Stanhope, K.L., Bremer, A.A., Medici, V., Nakajima, K. et al., Consumption of fructose and high fructose corn syrup increase postprandial triglycerides, LDL-cholesterol, and apolipoprotein-B in young men and women. J. Clin. Endocrinol. Metab. 2011, 96, E1596-E1605.

4. de Koning, L., Malik, V.S., Kellogg, M.D., Rimm, E.B. et al., Sweetened beverage consumption, incident coronary heart disease, and biomarkers of risk in men. Circulation 2012, 125(14), 1735-1741.

5. Heden, T.D., Liu, Y., Park, Y.M., Nyhoff, L.M. et al., Moderate amounts of fructose- or glucose-sweetened beverages do not differentially alter metabolic health in male and female adolescents. Am. J. Clin. Nutr. 2014, 100(3), 796-805.

6. Chiavaroli, L., de Souza, R.J., Ha, V., Cozma, A.I. et al., Effect of fructose on established lipid targets: A systematic review and meta-analysis of controlled feeding trials. J. Am. Heart Assoc. 2015, 4(9), e001700.

7. Lecoultre, V., Egli, L., Theytaz, F., Despland, C. et al., Fructose-induced hyperuricemia is associated with a decreased renal uric acid excretion in humans. Diabetes Care 2013, 36(9), e149-e150.

8. Lanaspa, M.A., Sanchez-Lozada, L.G., Choi, Y.J., Cicerchi, C. et al., Uric acid induces hepatic steatosis by generation of mitochondrial oxidative stress: potential role in fructose-dependent and -independent fatty liver. J. Biol. Chem. 2012, 287(48), 4073240744 . 
9. Rodríguez, L., Otero, P., Panadero, M.I., Rodrigo, S. et al., Maternal fructose intake induces insulin resistance and oxidative stress in male, but not female, offspring. J. Nutr. Metab. 2015, vol. 2015, Article ID 158091. doi:10.1155/2015/158091.

10. Castro, M.C., Massa, M.L., Del Zotto, H., Gagliardino, J.J. et al., Rat liver uncoupling protein 2: changes induced by a fructose-rich diet. Life Sci. 2011, 89(17-18), 609-614.

11. Francini, F., Castro, C., Schinella, G., Garcia, M.E. et al., Changes induced by a fructoserich diet on hepatic metabolism and the antioxidant system. Life Sci. 2010, 86, 965-971.

12. Rebolledo, O.R., Marra, C.A., Raschia, A., Rodríguez, S. et al., Abdominal adipose tissue: early metabolic dysfunction associated to insulin resistance and oxidative stress induced by an unbalanced diet. Horm. Metab. Res. 2008, 40, 794-800.

13. Koletzko, B., von Kries, R., Monasterolo, R.C., Subías, J.E. et al., European Childhood Obesity Trial Study Group, Infant feeding and later obesity risk. Adv. Exp. Med. Biol. 2009, 646, 15-29.

14. Beck, B., Richy, S., Archer, Z.A., Mercer, J.G., Ingestion of carbohydrate-rich supplements during gestation programs insulin and leptin resistance but not body weight gain in adult rat offspring. Front. Physiol. 2012, 3, 224.

15. Alzamendi, A., Castrogiovanni, D., Gaillard, R.C., Spinedi, E. et al., Increased male offspring's risk of metabolic-neuroendocrine dysfunction and overweight after fructoserich diet intake by the lactating mother. Endocrinology 2010, 151, 4214-4223.

16. Clayton, Z.E., Vickers, M.H., Bernal, A., Yap, C. et al., Early life exposure to fructose alters maternal, fetal and neonatal hepatic gene expression and leads to sex-dependent changes in lipid metabolism in rat offspring. PLoS ONE 2015, $10(11)$, e0141962.

17. Rodríguez, L., Panadero, M.I., Roglans, N., Otero, P. et al., Fructose during pregnancy affects maternal and fetal leptin signalling. J. Nutr. Biochem. 2013, 24, 1709-1716.

18. Rodríguez, L., Panadero, M.I., Roglans, N., Otero, P. et al., Fructose only in pregnancy provokes hyperinsulinemia, hypoadiponectinemia and impaired insulin signaling in adult male, but not female, progeny. Eur. J. Nutr. 2016, 55(2), 665-674.

19. Ching, R.H.H., Yeung, L.O.Y., Tse, I.M.Y., Sit, W-H. et al., Supplementation of bitter melon to rats fed a high-fructose diet during gestation and lactation ameliorates fructoseinduced dyslipidemia and hepatic oxidative stress in male offspring. J. Nutr. 2011, 141(9), 1664-1672.

20. Takehara, Y., Yoshioka, T., Sasaki, J., Changes in the levels of lipoperoxide and antioxidant factors in human placenta during gestation. Acta Medica Okayama 1990, 44(2), 103-111.

21. Qanungo, S., Mukherjea, M., Ontogenic profile of some antioxidants and lipid peroxidation in human placental and fetal tissues. Mol. Cell. Biochem. 2000, 215, 11-19.

22. Vickers, M.H., Clayton, Z.E., Yap, C., Sloboda, D.M., Maternal fructose intake during pregnancy and lactation alters placental growth and leads to sex-specific changes in fetal and neonatal endocrine function. Endocrinology 2011, 152(4), 1378-1387. 
23. Wong, S.H., Knight, J.A., Hopfer, S.M., Zaharia, O. et al., Lipoperoxides in plasma as measured by liquid chromatographic separation of malondialdehyde-thiobarbituric acid adduct. Clin. Chem. 1987, 33(2 Pt1), 214-220.

24. Levine, R.L., Garland, D., Oliver, C.N., Amici, A. et al., Determination of carbonyl content in oxidatively modified proteins. Methods Enzymol. 1990, 186, 464-478.

25. Witko-Sarsat, V., Friedlander, M., Khoa, T.N., Capeillere-Blandinet, C. et al., Advanced oxidation protein product as novel mediators of inflammation and monocytes activation in chronic renal failure. J. Immunol. 1998, 161, 2524-2532.

26. Maeso, N., Garcia-Martinez, D., Ruperez, F.J., Cifuentes, A. et al., Capillary electrophoresis of glutathione to monitor oxidative stress and response to antioxidant treatments in an animal model. J. Chromatography B 2005, 822(1), 61-69.

27. Rozen, S., Skaletsky, H., Primer3 on the WWW for general users and for biologist programmers. Methods Mol. Biol. 2000, 132, 365-386.

28. Pfaffl, M.W., A new mathematical model for relative quantification in real-time RTPCR. Nucleic Acids Res. 2001, 29(9), e45.

29. Goldberg, D.M., Spooner, R.J., Glutathione reductase. In: Bergmeyer HV (ed.). Methods in enzymatic analysis, $3^{\text {rd }}$ edition. Weinheim:Verlag-Chemie. Vol III, pp 258-265, 1987.

30. Gunzler, W.A., Kremers, H., Flohe, L., An improved coupled test procedure for glutathione peroxidase (EC 1-11-1-9) in blood. Z Klin. Chem. Klin. Biochem. 1974, 12(10), 444-448.

31. Aebi, H., Catalase. In: Bergmeyer HV (ed.). Methods in enzymatic analysis, $3^{\text {rd }}$ edition. Weinheim: Verlag-Chemie. Vol III, pp 273-282, 1987.

32. Sodhi, K., Puri, N., Favero, G., Stevens, S. et al., Fructose mediated non-alcoholic fatty liver is attenuated by HO-1-SIRT1 module in murine hepatocytes and mice fed a high fructose diet. PLoS ONE 2015, 10(6), e0128648.

33. Khitan, Z., Harsh, M., Sodhi, K., Shapiro, J.I. et al., HO-1 upregulation attenuates adipocyte dysfunction, obesity, and isoprostane levels in mice fed high fructose diets. $J$. Nutr. Metab. 2014, vol. 2014, Article ID 980547, 2014. doi:10.1155/2014/980547.

34. Kansanen, E., Kuosmanen, S.M., Leinonen, H., Levonen, A.L., The Keap1-Nrf2 pathway: Mechanisms of activation and dysregulation in cancer. Redox Biol. 2013, 1, 45 49.

35. Martin, D., Li, Y., Yang, J., Wang, G. et al., Unspliced X-box-binding protein 1 (XBP1) protects endothelial cells from oxidative stress through interaction with histone deacetylase 3. J. Biol. Chem. 2014, 289(44), 30625-30634.

36. Januiaux, E., Watson, A.L., Hempstock, J., Bao, Y-P. et al., Onset of maternal arterial blood flow and placental oxidative stress. A possible factor in human early pregnancy failure. Am. J. Pathol. 2000, 157, 2111-2122.

37. Moukdar, F., Robidoux, J., Lyght, O., Pi, J. et al., Reduced antioxidant capacity and dietinduced atherosclerosis in uncoupling protein-2-deficient mice. J. Lipid Res. 2009, 50, 59-70. 
38. Spolarics, Z., Meyenhofer, M., Augmented resistance to oxidative stress in fatty rat livers induced by a short-term sucrose-rich diet. Biochim. Biophys. Acta 2000, 1487:190-200.

39. Herrera, E., Lasunción, M.A., Gomez-Coronado, D., Aranda, P. et al., Role of lipoprotein lipase activity on lipoprotein metabolism and the fate of circulating triglycerides in pregnancy. Am. J. Obstet. Gynecol. 1988, $158(6$ Pt 2):1575-1583.

40. González, M.C., Vidal, H., Herrera, E., Bocos, C., Fenofibrate reduces adiposity in pregnant and virgin rats but through different mechanisms. BMB Reports 2009, 42(10), 679-684.

41. Busserolles, J., Mazur, A., Gueux, E., Rock, E. et al., Metabolic syndrome in the rat: females are protected against the pro-oxidant effect of a high sucrose diet. Exp. Biol. Med. 2002, 227, 837-842.

42. Álvarez, J.J., Montelongo, A., Iglesias, A., Lasunción, M.A. et al., Longitudinal study on lipoprotein profile, high density lipoprotein subclass, and postheparin lipases during gestation in women. J. Lipid Res. 1996, 37, 299-308.

43. Matafome, P., Sena, C., Seiça, R., Methylglyoxal, obesity, and diabetes. Endocrine 2013, $43,472-484$.

44. Herrera, E., Lasunción, M.A., Asunción, M., Placental transport of free fatty acids, glycerol and ketone bodies. In: Fetal and Neonatal Physiology (Polin R, Fox WW, eds.), pp. 291-298. WB Saunders, Philadelphia, PA, USA, 1992.

45. Asghar, Z.A., Thompson, A., Chi, M., Cusumano, A. et al., Maternal fructose drives placental uric acid production leading to adverse fetal outcomes. Sci. Rep. 2016, 6, 25091.

46. Kovacevic, S., Nestorov, J., Matic, G., Elakovic, I., Fructose-enriched diet induces inflammation and reduces antioxidative defense in visceral adipose tissue of young female rats. Eur. J. Nutr. 2015, doi:10.1007/s00394-015-1065-0, (on-line).

47. Saben, J.L., Asghar, Z., Rhee, J.S., Drury, A. et al., Excess maternal fructose consumption increases fetal loss and impairs endometrial decidualization in mice. Endocrinology 2016, 157, 956-968.

48. Perez, M.J., Macías, R.I.R., Marín, J.J.G., Maternal cholestasis induces placental oxidative stress and apoptosis. Protective effect of ursodeoxycholic acid. Placenta 2006, 27, 34-41.

49. Ozen. M., Zhao, H., Lewis, D.B., Wong, R.J. et al., Heme oxygenase and the immune system in normal and pathological pregnancies. Front. Pharmacol. 2015, 6, 84. doi: 10.3389/fphar.2015.00084.

50. Borgen, I., Aamodt, G., Harsem, N., Haugen, M. et al., Maternal sugar consumption and risk of preeclampsia in nulliparous Norwegian women. Eur. J. Clin. Nutr. 2012, 66, 920-925.

51. Kendig, M.D., Ekayanti, W., Stewart, H., Boakes, R.A. et al., Metabolic effects of access to sucrose drink in female rats and transmission of some effects to their offspring. PLoS One 2015, 10(7), e0131107. 
52. Rodríguez-Rodríguez, P., de Pablo, A.L., Condezo-Hoyos, L., Martín-Cabrejas, M.A. et al., Fetal undernutrition is associated with perinatal sex-dependent alterations in oxidative status. J. Nutr. Biochem. 2015, 26(12), 1650-1659.

53. Rebollo, A., Roglans, N., Baena, M., Sánchez, R.M. et al., Liquid fructose downregulates Sirtl expression and activity and impairs the oxidation of fatty acids in rat and human liver cells. Biochim. Biophys. Acta 2014, 1841, 514-524. 


\section{Legends}

Fig. 1. Maternal ingestion of a $10 \% \mathrm{w} / \mathrm{v}$ fructose solution throughout gestation does affect maternal oxidative stress in plasma, liver and lumbar adipose tissue. (A) Plasma MDA values of control, fructose- and glucose-fed 20-day-pregnant rats. (B) Hepatic MDA values of control, fructose- and glucose-fed pregnant rats. (C) Adipose MDA values of control, fructose- and glucose-supplemented pregnant rats. Results are the mean \pm S.E. of values from 6-7 rats. Small letters correspond to the statistical comparisons between rats receiving different supplementation into the drinking water. Values not sharing a common letter are significantly different at $\mathrm{p}<0.05$.

Fig. 2. Maternal ingestion of a $10 \% \mathrm{w} / \mathrm{v}$ fructose solution throughout gestation affects oxidative stress in fetal plasma and liver and in placenta. (A) Plasma MDA values of fetuses from control, fructose- and glucose-fed pregnant rats. (B) Hepatic MDA values of fetuses from control, fructose- and glucose-fed mothers. (C) Placental MDA values of control, fructose- and glucosefed 20-day-pregnant rats. Results are the mean \pm S.E. of values from 6-7 fetal plasma, liver or placenta pools of the same litter. Small letters correspond to the statistical comparisons between rats receiving different supplementation into the drinking water. Values not sharing a common letter are significantly different at $\mathrm{p}<0.05$.

Fig. 3. Maternal intake of a $10 \% \mathrm{w} / \mathrm{v}$ fructose solution throughout gestation affects maternal liver and placenta HO-1 mRNA gene expression. (A) Relative hepatic levels of specific mRNA for heme oxygenase-1 (HO-1) of control (empty bar), fructose- (black bar) and glucose-fed (grey bar) 20-day-pregnant rats. (B) Relative hepatic levels of specific mRNA for HO-1 of fetuses from control (empty bar), fructose- (black bar), and glucose-fed (grey bar) pregnant rats. (C) Relative hepatic levels of specific mRNA for HO-1 of placentas from control (empty bar), fructose- (black bar), and glucose-fed (grey bar) pregnant rats. Relative target gene mRNA levels were measured by Real Time PCR, as explained in Materials and Methods, and normalized to Rps29 levels and expressed in arbitrary units (a.u.). Each bar represents the mean \pm S.E. of values from 6-7 animals. RNA was prepared from maternal liver and fetal liver or placenta pools of the same litter. Small letters correspond to the statistical comparisons between fetuses from mothers receiving different supplementation into the drinking water. Values not sharing a common letter are significantly different at $\mathrm{p}<0.05$. 
Fig. 4. Maternal intake of a $10 \% \mathrm{w} / \mathrm{v}$ fructose solution throughout gestation affects placental Nrf2 and HO-1 protein expression. Nrf2 (A) and HO-1 (B) protein levels determined by Western blot. Bars represent the mean \pm S.E. of values obtained from five placenta pools of the same litter. Small letters correspond to the statistical comparisons between placentas from mothers receiving different supplementation into the drinking water. Values not sharing a common letter are significantly different at $p<0.05$. (C) Representative western blots corresponding to 3 different control, fructose-, and glucose-fed rats are shown. 
Table 1

Oxidative stress markers and antioxidant system in fructose- or glucose- supplemented pregnant rats

\begin{tabular}{|l|c|c|c|}
\hline & Control & Fructose & Glucose \\
\hline Plasma & \multicolumn{3}{|c|}{ Oxidative stress markers } \\
\hline $\begin{array}{l}\text { Protein carbonylation (nmol/mg } \\
\text { protein) }\end{array}$ & $1.78 \pm 0.14$ & $2.11 \pm 0.08$ & $1.70 \pm 0.17$ \\
\hline Uric acid (mg/dL) & $3.15 \pm 0.42^{\mathrm{a}}$ & $5.91 \pm 0.31^{\mathrm{b}}$ & $3.91 \pm 0.37^{\mathrm{a}}$ \\
\hline Liver & \multicolumn{3}{|c|}{ Oxidative stress markers } \\
\hline $\begin{array}{l}\text { Protein carbonylation (nmol/mg } \\
\text { protein) }\end{array}$ & $2.38 \pm 0.06^{\mathrm{a}}$ & $2.89 \pm 0.09^{\mathrm{b}}$ & $2.65 \pm 0.04^{\mathrm{b}}$ \\
\hline Uric acid ( $\mu \mathrm{g} / \mathrm{mg}$ protein) & $0.498 \pm 0.050^{\mathrm{a}}$ & $0.715 \pm 0.023^{\mathrm{b}}$ & $0.709 \pm 0.032^{\mathrm{b}}$ \\
\hline & $10.8 \pm 0.8$ & $21.8 \pm 3.4$ & $21.1 \pm 5.0$ \\
\hline GSH/GSSG ratio & $260.7 \pm 19.8$ & $254.8 \pm 15.7$ & $222.2 \pm 14.0$ \\
\hline Catalase (mU/mg protein) & $2.16 \pm 0.04^{\mathrm{b}}$ & $1.80 \pm 0.06^{\mathrm{a}}$ & $1.91 \pm 0.14^{\mathrm{ab}}$ \\
\hline Gpx1 activity (U/mg protein) & $46.1 \pm 1.3$ & $43.9 \pm 0.3$ & $42.7 \pm 1.5$ \\
\hline GR activity (mU/mg protein) & $8.25 \pm 0.66$ & $5.84 \pm 0.67$ & $7.57 \pm 1.44$ \\
\hline SOD1 activity (U/mg protein) & $29.3 \pm 1.3$ & $31.1 \pm 2.1$ & $30.0 \pm 2.6$ \\
\hline SOD2 activity (U/mg protein) & & & \\
\hline
\end{tabular}

Data are $\mathrm{M} \pm \mathrm{SE}$, from 6-7 pregnant rats per group. Different letters indicate significant differences between the groups $(P<0.05)$. 
Table 2

Oxidative stress markers and antioxidant system in fetuses and placentas from fructoseor glucose- supplemented pregnant rats

\begin{tabular}{|c|c|c|c|}
\hline & Control & Fructose & Glucose \\
\hline Fetal plasma & \multicolumn{3}{|c|}{ Oxidative stress markers } \\
\hline $\begin{array}{l}\text { Protein carbonylation (nmol/mg } \\
\text { protein) }\end{array}$ & $1.50 \pm 0.07$ & $1.64 \pm 0.13$ & $1.38 \pm 0.15$ \\
\hline Uric acid $(\mathrm{mg} / \mathrm{dL})$ & $2.21 \pm 0.34$ & $1.89 \pm 0.15$ & $2.25 \pm 0.16$ \\
\hline Fetal liver & \multicolumn{3}{|c|}{ Oxidative stress markers } \\
\hline $\begin{array}{l}\text { Protein carbonylation (nmol/mg } \\
\text { protein) }\end{array}$ & $2.26 \pm 0.04$ & $2.48 \pm 0.05$ & $2.32 \pm 0.10$ \\
\hline Uric acid $(\mu \mathrm{g} / \mathrm{mg}$ protein $)$ & $0.488 \pm 0.043^{\mathrm{a}}$ & $0.651 \pm 0.050^{b}$ & $0.558 \pm 0.021^{\text {at }}$ \\
\hline & \multicolumn{3}{|c|}{ Antioxidant system } \\
\hline GSH/GSSG ratio & $17.8 \pm 3.2$ & $19.3 \pm 2.8$ & $20.0 \pm 2.8$ \\
\hline Catalase (mU/mg protein) & $166.9 \pm 4.1$ & $166.6 \pm 7.5$ & $167.6 \pm 6.7$ \\
\hline Gpx1 activity (U/mg protein) & $1.14 \pm 0.04$ & $1.03 \pm 0.02$ & $1.04 \pm 0.04$ \\
\hline GR activity (mU/mg protein) & $28.2 \pm 1.3^{\mathrm{a}}$ & $32.2 \pm 0.3^{b}$ & $28.9 \pm 0.9^{\mathrm{ab}}$ \\
\hline SOD1 activity (U/mg protein) & $0.64 \pm 0.10^{\mathrm{a}}$ & $1.18 \pm 0.13^{b}$ & $0.67 \pm 0.12^{\mathrm{a}}$ \\
\hline SOD2 activity (U/mg protein) & $4.09 \pm 0.07$ & $4.20 \pm 0.16$ & $4.21 \pm 0.12$ \\
\hline Placenta & \multicolumn{3}{|c|}{ Oxidative stress markers } \\
\hline $\begin{array}{l}\text { Protein carbonylation (nmol/mg } \\
\text { protein) }\end{array}$ & $2.33 \pm 0.41^{\mathrm{a}}$ & $3.93 \pm 0.37^{b}$ & $2.59 \pm 0.34^{\mathrm{ab}}$ \\
\hline \multirow[t]{2}{*}{ Uric acid $(\mu \mathrm{g} / \mathrm{mg}$ protein $)$} & $0.855 \pm 0.053$ & $0.820 \pm 0.034$ & $0.838 \pm 0.030$ \\
\hline & \multicolumn{3}{|c|}{ Antioxidant system } \\
\hline GSH/GSSG ratio & $9.56 \pm 1.46$ & $8.69 \pm 0.96$ & $8.26 \pm 0.68$ \\
\hline Catalase (mU/mg protein) & $25.5 \pm 0.7^{b}$ & $24.6 \pm 0.3^{b}$ & $19.7 \pm 0.2^{\mathrm{a}}$ \\
\hline Gpx1 activity (U/mg protein) & $0.926 \pm 0.026$ & $0.922 \pm 0.030$ & $0.907 \pm 0.018$ \\
\hline GR activity (mU/mg protein) & $18.0 \pm 0.8$ & $16.2 \pm 0.2$ & $20.2 \pm 1.6$ \\
\hline SOD1 activity (U/mg protein) & $0.164 \pm 0.018$ & $0.190 \pm 0.007$ & $0.157 \pm 0.022$ \\
\hline SOD2 activity (U/mg protein) & $0.673 \pm 0.025^{\mathrm{a}}$ & $0.778 \pm 0.018^{b}$ & $0.704 \pm 0.013^{\mathrm{a}}$ \\
\hline
\end{tabular}

Data are $M \pm S E$ from $n=6-7$ liver pools of the fetuses of the same litter or $n=6-7$ placental pools of the same litter. Different letters indicate significant differences between the groups $(P<$ $0.05)$. 
Table 3

Gene expression (mRNA) in the liver and placenta of fructose- or glucosesupplemented pregnant rats and their fetuses.

\begin{tabular}{|l|c|c|c|}
\hline & Control & Fructose & Glucose \\
\hline Maternal liver expression & & & \\
\hline NOQ1 (a.u.) & $3.50 \pm 0.16^{\mathrm{b}}$ & $2.61 \pm 0.11^{\mathrm{a}}$ & $2.66 \pm 0.07^{\mathrm{a}}$ \\
\hline HDAC3 (a.u.) & $1.92 \pm 0.07^{\mathrm{a}}$ & $2.22 \pm 0.07^{\mathrm{b}}$ & $2.23 \pm 0.11^{\mathrm{b}}$ \\
\hline XBP1u (a.u.) & $2.17 \pm 0.26^{\mathrm{b}}$ & $1.53 \pm 0.07^{\mathrm{a}}$ & $1.23 \pm 0.04^{\mathrm{a}}$ \\
\hline Fetal liver expression & & & \\
\hline NOQ1 (a.u.) & $0.66 \pm 0.09$ & $0.59 \pm 0.03$ & $0.66 \pm 0.08$ \\
\hline HDAC3 (a.u.) & $0.82 \pm 0.04$ & $0.77 \pm 0.05$ & $0.78 \pm 0.03$ \\
\hline XBP1u (a.u.) & $0.24 \pm 0.02$ & $0.25 \pm 0.02$ & $0.26 \pm 0.01$ \\
\hline Placental expression & & & \\
\hline NOQ1 (a.u.) & $0.52 \pm 0.02^{\mathrm{b}}$ & $0.34 \pm 0.03^{\mathrm{a}}$ & $0.44 \pm 0.05^{\mathrm{ab}}$ \\
\hline HDAC3 (a.u.) & $2.06 \pm 0.30^{\mathrm{ab}}$ & $1.57 \pm 0.20^{\mathrm{a}}$ & $2.76 \pm 0.15^{\mathrm{b}}$ \\
\hline XBP1u (a.u.) & $0.45 \pm 0.05$ & $0.47 \pm 0.08$ & $0.45 \pm 0.07$ \\
\hline
\end{tabular}

$\mathrm{M} \pm \mathrm{SE}, \mathrm{n}=6-7$ pregnant rats; $\mathrm{n}=6-7$ liver pools of the fetuses of the same litter; $n=6-7$ placental pools of the same litter. Different letters indicate significant differences between the groups $(P<0.05)$. Relative target gene mRNA levels were measured by Real Time PCR, as explained in Materials and Methods, and normalized to Rps29 levels and expressed in arbitrary units (a.u.). 
14
15

15
16

17
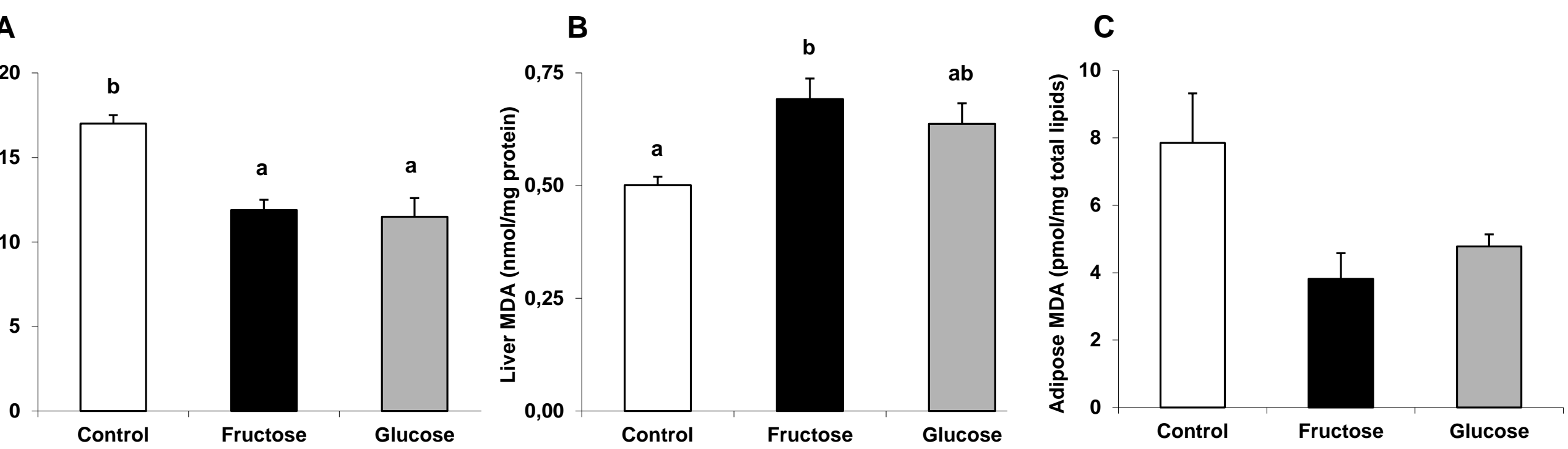
A B

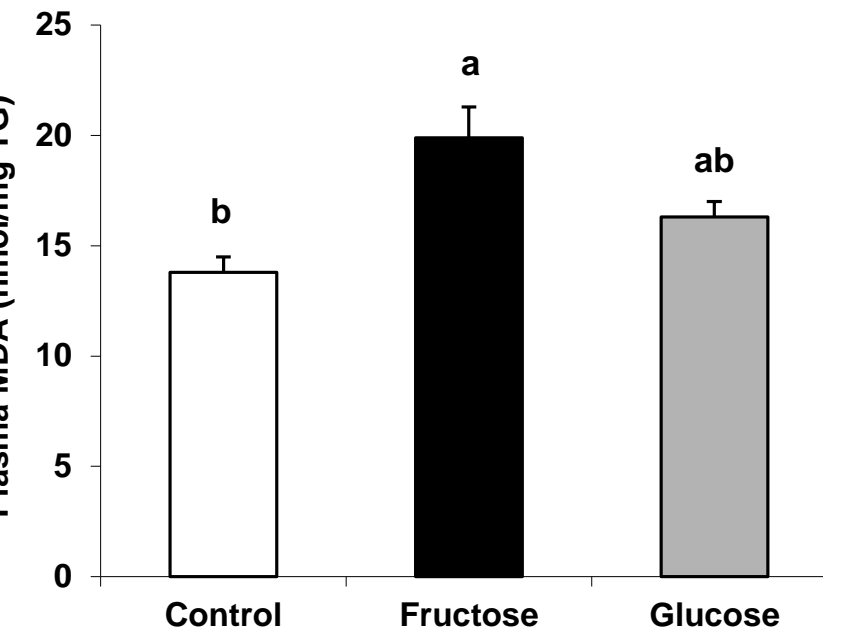

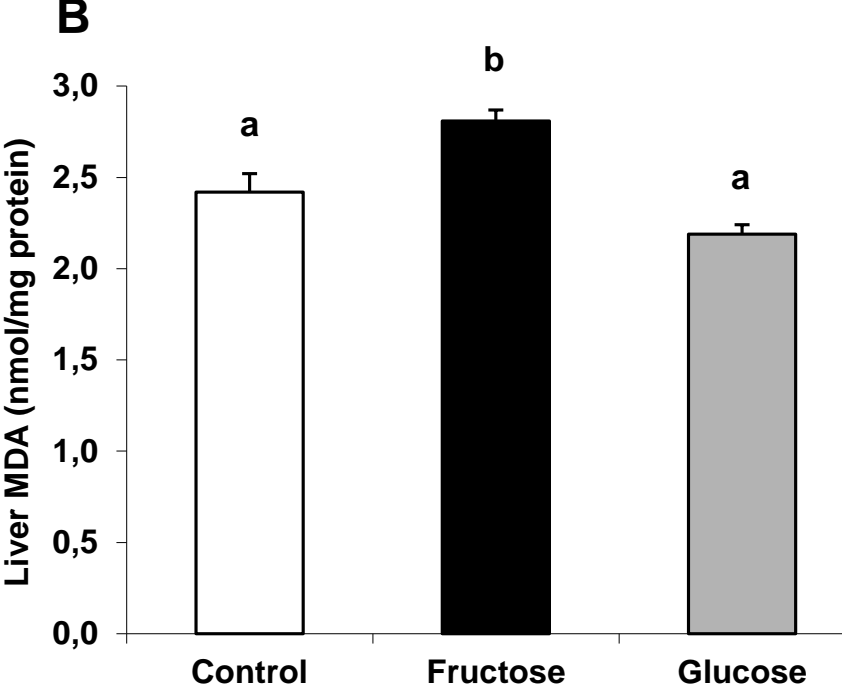

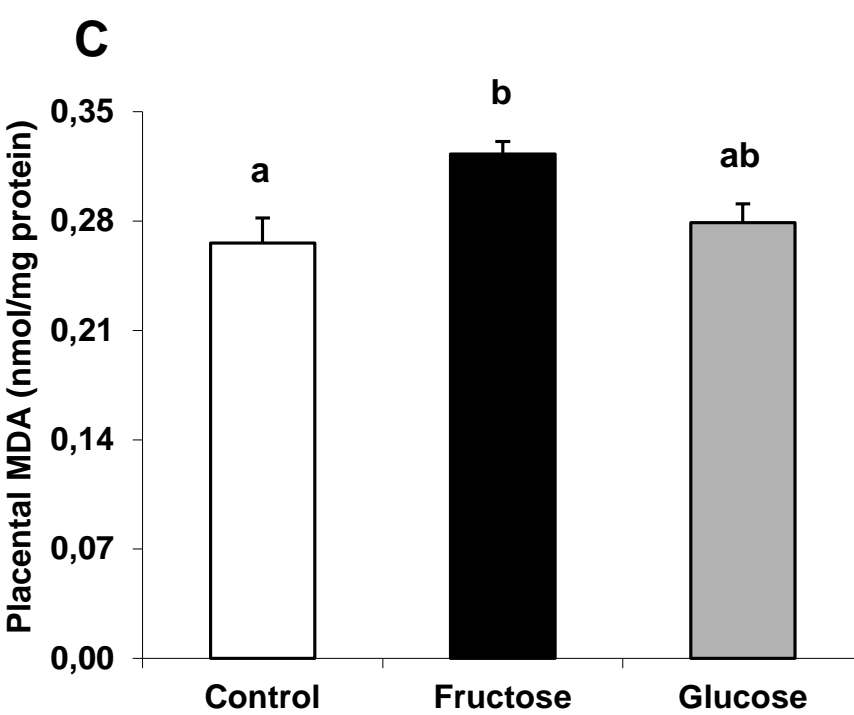


A

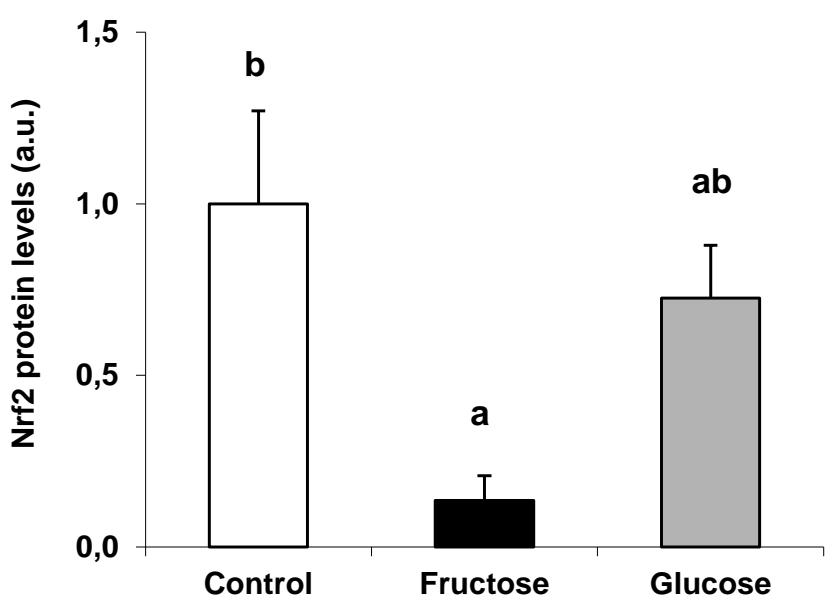

B

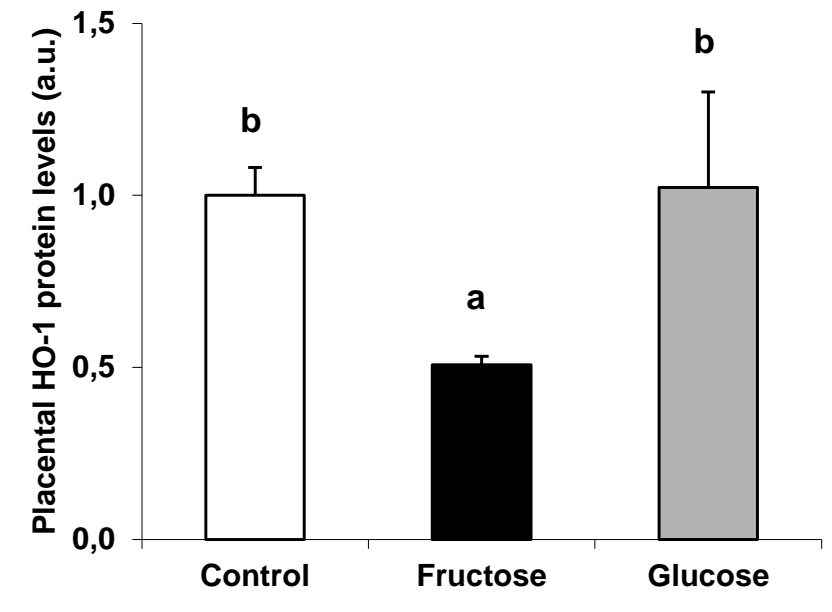

C
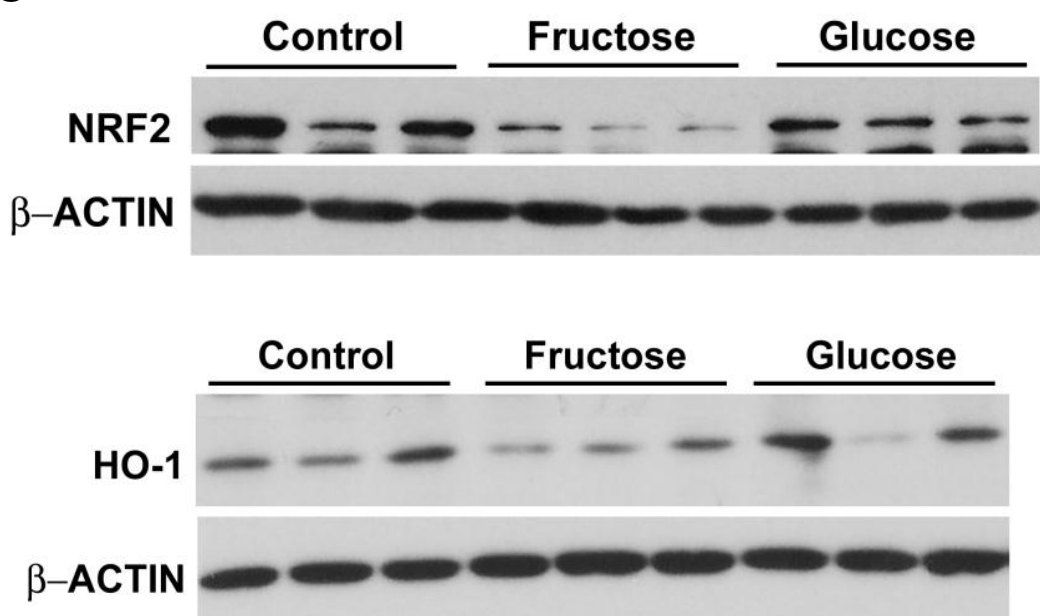


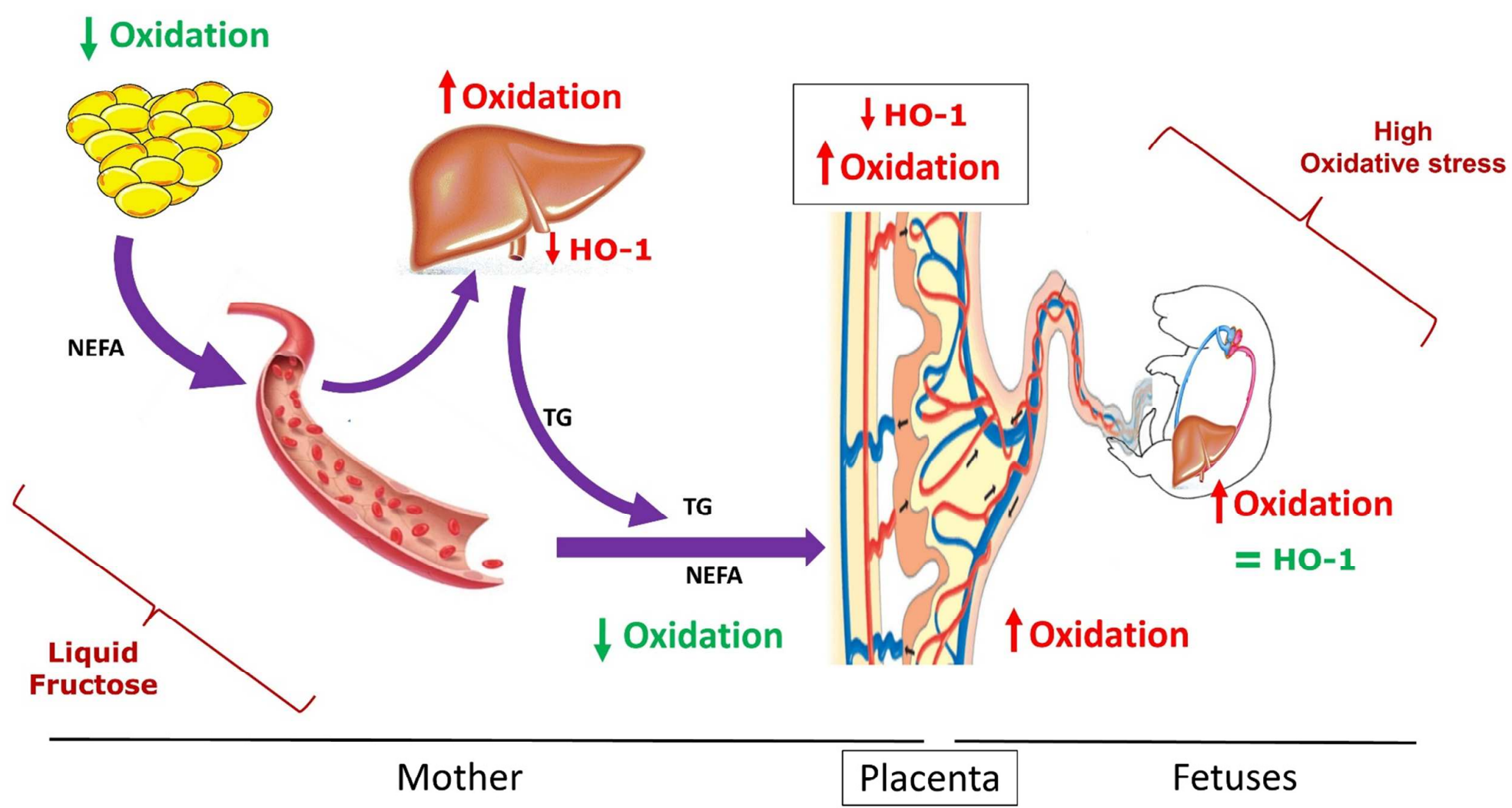

One of the features of metabolic syndrome caused by liquid fructose intake is an impairment of redox status. Liquid fructose only in pregnancy leads to maternal hepatic oxidative stress, mainly due to a diminution in heme oxygenase-1 (HO-1) expression, a potent antioxidant gene. Surprisingly, mothers fed fructose displayed low plasma lipid oxidation. In contrast, fetuses from fructose-fed mothers showed high levels of plasma lipoperoxidation. Interestingly, an augmented oxidative stress was observed in placenta of fructose-fed mothers, accompanied by a lower HO-1 expression. 